\title{
CES
}

COOPERATIVISMO E ECONOMÍA SOCIAL

Núm. 42 (2019-2020), páxs. 299-306

ISSN: $2660-6348$

\section{LA MODIFICACIÓN DEL CONSEJO PARA EL FOMENTO DE LA ECONOMÍA SOCIAL}

\section{THE MODIFICATION OF THE COUNCIL FOR THE PROMOTION OF THE SOCIAL ECONOMY}

\author{
María Jesús Rodríguez MigueZ* \\ José Antonio Rodríguez MígueZ**
}

\footnotetext{
Abogada del ICA de Pontevedra. Dirección de correo electrónico: mjrmiguez@mundo-r.com

** Doctor en Derecho. Miembro del IDIUS y CERGI, de la USC. Dirección de correo electrónico: jarmiguez@gmail.com
} 


\title{
RESUMO
}

La economía social, cuya relevancia nadie puede desconocer hoy en día, ha adquirido en nuestro país y en el ámbito de la Unión Europea una importante dimensión que la actual crisis hace más necesaria.

La norma examinada en la presente crónica supone una adaptación y modernización de carácter técnico de las reglas de organización y funcionamiento del Consejo para el Fomento de la Economía Social, de 2001, a las normas básicas de organización y funcionamiento del sector público recogidas en las leyes 39 y $40 / 2015$.

Su eficacia deberá demostrase por su actividad efectiva como órgano consultivo y de asesoramiento, especialmente cuando la crisis sanitaria generada por la pandemia de COVID-19 ha devenido en crisis económica y social.

Palavras clave: Economía Social, Cooperativas, Cooperativismo,

\begin{abstract}
The social economy, whose relevance no one can ignore today, has acquired an important dimension in our country and within the European Union that the current crisis makes all the more necessary.

The norm examined in this chronicle supposes an adaptation and modernization of a technical nature of the rules of organization and operation of the Council for the Promotion of the Social Economy, of 2001, to the basic norms of organization and operation of the public sector contained in the laws 39 and 40/2015.

Its effectiveness should be demonstrated by its effective activity as a consultative and advisory body, especially when the health crisis generated by the COVID-19 pandemic has turned into an economic and social crisis.
\end{abstract}

KeYworlds: Social Economy, Cooperatives, Cooperativism. 
SUMARIO: I. PRESENTACIÓN. II. LA DENOMINADA ECONOMÍA SOCIAL Y LA IMPORTANCIA DE SU FOMENTO. III. EL CONSEJO PARA EL FOMENTO DE LA ECONOMÍA SOCIAL. IV. LOS CAMBIOS INTRODUCIDOS EN SU ORGANIZACIÓN Y FUNCIONAMIENTO. V. VALORACIÓN.

SUMMARY: I. PRESENTATION. II. THE SO-CALLED SOCIAL ECONOMY AND THE IMPORTANCE OF ITS PROMOTION. III. THE COUNCIL FOR THE PROMOTION OF THE SOCIAL ECONOMY. IV. THE CHANGES INTRODUCED IN ITS ORGANIZATION AND OPERATION. V. VALUATION.

\section{Presentación}

$\square$ 1 Boletín Oficial del Estado (BOE) n. ${ }^{\circ}$ 47, del 24 febrero 2021 publicó el Real Decreto 117/2021, de 23 de febrero por el que se modifica el Real Decreto 219/2001, de 2 de marzo, sobre organización y funcionamiento del Consejo para el Fomento de la Economía Social.

El objeto de la presente crónica es examinar las novedades introducidas por este Real Decreto 117/2021 en un órgano esencial para el fomento de la economía social en España como es el Consejo para el Fomento de la Economía Social (en adelante "CFES" o simplemente "el Consejo"), encuadrada esta institución en el ámbito de la denominada "Economía Social" cuya importancia resulta mayor si cabe en circunstancias como las actuales, marcadas por los negativos efectos sociales y económicos derivados de una crisis sanitaria sin precedentes como la ocasionada por la pandemia de COVID-19.

Por ello, y tras exponer brevemente el fundamento de la denominada Economía Social, abordaremos el papel asignado a este Consejo y el alcance de las modificaciones introducidas en su organización y funcionamiento por el Real Decreto $117 / 2021$.

\section{LA DENOMINADA ECONOMÍA SOCIAL Y LA IMPORTANCIA DE SU FOMENTO}

Desde la perspectiva de nuestro derecho positivo nacional, la referencia básica de la economía social en España es la Ley 5/2011, de 29 de marzo, de Economía Social (en adelante, LES).

Como se recoge en su Preámbulo "El marco histórico de nacimiento del concepto moderno de Economía Social se estructura a través de las primeras experiencias cooperativas, asociativas y mutualistas que surgen desde finales del siglo XVIII y se desarrollan a lo largo del siglo XIX en distintos países de Europa (In- 
glaterra, Italia, Francia o España). A partir de este concepto tradicional de origen decimonónico que engloba a las cooperativas, mutualidades, fundaciones y asociaciones, se fueron sucediendo en la década de los años 70 y 80 del pasado siglo y en distintos países europeos, declaraciones que caracterizan la identificación de la economía social en torno a distintos principios. (...)"

Desde la perspectiva europea hubo que esperar hasta 1992 para que el Comité Económico y Social Europeo presentase tres Propuestas de Reglamento de Estatutos de la Asociación Europea, de la Cooperativa Europea y de la Mutualidad Europea, aunque de las tres sólo llegó a materializarse el Reglamento por el que se aprueba el Estatuto de la Sociedad Cooperativa Europea (Reglamento CE 1435/2003 del Consejo, de 22 de julio de 2003) y la Directiva por la que se completa el Estatuto de la Sociedad Cooperativa Europea en lo que respecta a la implicación de los trabajadores (Directiva 2003/72/CE del Consejo, de 22 de julio), en buena medida, gracias al impulso de Alemania cuya legislación se haya inspirada en la conocida como "Economía Social de Mercado" matizando la clásica "Economía de Mercado" con la relevancia de su dimensión social.

En el caso de España, además del reconocimiento de las sociedades cooperativas y otras formas de sociedad de lo que hoy ya conocemos como economía social, debemos recordar que la economía social obtiene un reconocimiento implícito en nuestro texto constitucional de 1978, puesto que diversos artículos del mismo hacen referencia, de forma genérica o específica, a alguna de las entidades que hoy reunimos bajo la denominación de "economía social" como sucede en el artículo 1.1, en el artículo 129.2 o la propia cláusula de igualdad social del artículo 9.2, y otros artículos concretos como el 40, el 41 y el 47, que plasman el fuerte arraigo de las citadas entidades en el texto constitucional, como expresivamente se recoge en el apartado II del Preámbulo de la LES.

En realidad, no fue hasta 1990 cuando la economía social empieza a tener un reconocimiento expreso por parte de las instituciones públicas, con ocasión de la creación del Instituto Nacional de Fomento de la Economía Social (INFES), por la Ley 31/1990, de 27 de diciembre, que sustituía a la Dirección General de Cooperativas y Sociedades Laborales del Ministerio de Trabajo y Seguridad Social que, entre cuyos objetivos figuraba ya el fomento de las entidades de economía social.

No se contará, sin embargo, de un marco definido y de una definición de economía social y de sus principios hasta la aprobación de la citada Ley 5/2011, de 29 de marzo, que ya nos ofrece un concepto propio de economía social (Artículo 2. Concepto y denominación) y enuncia sus principios orientadores (Artículo 4. Principios orientadores).

Así, conforme al citado Artículo 2 de la LES: 
"Se denomina economía social al conjunto de las actividades económicas y empresariales, que en el ámbito privado llevan a cabo aquellas entidades que, de conformidad con los principios recogidos en el artículo 4, persiguen bien el interés colectivo de sus integrantes, bien el interés general económico o social, o ambos."

Por su parte, el Artículo 4 de la LES enuncia como Principios orientadores de la actuación de las entidades de la economía social los siguientes:

“a) Primacía de las personas y del fin social sobre el capital, que se concreta en gestión autónoma y transparente, democrática y participativa, que lleva a priorizar la toma de decisiones más en función de las personas y sus aportaciones de trabajo y servicios prestados a la entidad o en función del fin social, que en relación a sus aportaciones al capital social.

b) Aplicación de los resultados obtenidos de la actividad económica principalmente en función del trabajo aportado y servicio o actividad realizada por las socias y socios o por sus miembros y, en su caso, al fin social objeto de la entidad.

c) Promoción de la solidaridad interna y con la sociedad que favorezca el compromiso con el desarrollo local, la igualdad de oportunidades entre hombres y mujeres, la cohesión social, la inserción de personas en riesgo de exclusión social, la generación de empleo estable y de calidad, la conciliación de la vida personal, familiar y laboral y la sostenibilidad.

d) Independencia respecto a los poderes públicos."

Sobre la base de estos principios la LES desarrolla el marco normativo español con una clara voluntad de fomentar el enfoque social de la economía, para lo que ya se había creado, en su momento, un Consejo para el Fomento de la Economía Social.

\section{El Consejo PARA EL Fomento de la ECONOMía Social}

En efecto, el origen del Consejo para el Fomento de la Economía Social se debe a la disposición adicional segunda de la Ley 27/1999, de 16 de julio, de Cooperativas, que había creado un Consejo para el Fomento de la Economía Social, configurándolo, como recuerda nuevamente en el Real Decreto 117/2021, como un órgano asesor y consultivo para las actividades relacionadas con la economía social, integrado, a través del entonces Ministerio de Trabajo y Asuntos Sociales, en la Administración General del Estado, aunque sin participar en la 
estructura jerárquica de esta y actuando como un órgano de colaboración y coordinación del movimiento asociativo y la Administración General del Estado.

Por su parte, la disposición final quinta de la citada Ley 27/1999, de Cooperativas, atribuía al Gobierno de España la potestad para dictar normas para la aplicación y desarrollo de la mencionada ley, que fue la base jurídica inmediata para la aprobación del Real Decreto 219/2001, de 2 de marzo, sobre organización y funcionamiento del Consejo para el Fomento de la Economía Social, que es la norma cuya reforma acomete el Real Decreto 117/2021, objeto del presente comentario.

Con posterioridad sería la ya citada Ley 5/2011, de Economía Social, la que configuraría el marco jurídico propio, más amplio que el específico de las cooperativas, lo que supuso el reconocimiento y mejora de la visibilidad de la economía social, otorgándole, al mismo tiempo, una mayor seguridad jurídica para no sólo definir, como ya hemos visto, la noción de economía social, sino también exponer sus principios orientadores que deben guiar a las distintas entidades que la forman.

El artículo 13 de esta LES regulaba ya el Consejo para el Fomento de la Economía Social, desde una perspectiva más amplia, como corresponde a la propia norma, como un órgano asesor y consultivo en la materia, indicándose que su funcionamiento y composición serán objeto de desarrollo reglamentario, y se ajustaría a lo dispuesto sobre órganos colegiados en la por aquel entonces todavía vigente Ley 30/1992, de 26 de noviembre, de Régimen Jurídico de las Administraciones Públicas y del Procedimiento Administrativo Común, y en la también hoy derogada Ley 6/1997, de 14 de abril, de Organización y Funcionamiento de la Administración General del Estado.

El objetivo del presente Real Decreto 117/2021 no es otro, en consecuencia, que adaptar las reglas de organización y funcionamiento de dicho Consejo a las reglas establecidas en las normas que reemplazan a las anteriores, esto es, a la Ley 39/2015, del Procedimiento Administrativo Común de las Administraciones Públicas, y a la Ley 40/2015, de 1 de octubre, de Régimen Jurídico del Sector Público, respectivamente.

\section{LOS CAMBIOS INTRODUCIDOS EN SU ORGANIZACIÓN Y FUNCIONAMIENTO.}

Situado en su necesario contexto, podemos ya exponer las novedades que introduce el Real Decreto 117/2021, como consecuencia de su necesaria adaptación a las leyes 39 y 40/2015. Las modificaciones introducidas en la redacción del Real Decreto 219/2001 afectan a la redacción de sus artículos 1, 2, 3, 4, 8, 12 y 13, la disposición adicional única, que pasa a ser la disposición adicional primera, y se introduce una disposición adicional segunda, relativa al uso de lenguaje no 
sexista, así como la disposición final primera del Real Decreto 219/2001, de 2 de marzo. Nos limitaremos a exponer únicamente los cambios más significativos.

El nuevo artículo 1, dedicado a su Objeto, deja de ser una remisión a la disposición adicional segunda de la Ley 27/1999, de 16 de julio, de Cooperativas, siendo su nueva redacción de carácter sustantivo y descriptivo. Queda redactado como sigue:

«Artículo 1. Objeto.

El Consejo para el Fomento de la Economía Social se configura como un órgano colegiado, asesor y consultivo para las actividades relacionadas con la economía social, integrado, a través del Ministerio de Trabajo y Economía Social, en la Administración General del Estado, sin participar de la estructura jerárquica de esta. Actuará como un órgano de colaboración, coordinación e interlocución de la economía social y la Administración General del Estado.»

La modificación de los apartados 1 y 3 del artículo 2 (Funciones y ámbito del Consejo) amplia y detalla su contenido:

«1. El Consejo para el Fomento de la Economía Social tendrá las funciones siguientes:

a) Informar y colaborar en la elaboración de proyectos sobre cualquier disposición legal o reglamentaria que afecten a entidades de la economía social.

b) Elaborar los informes que se soliciten por el Ministerio de Trabajo y Economía Social y demás departamentos ministeriales.

c) Evacuar informe previo en la elaboración y actualización del catálogo de entidades de la economía social del Ministerio de Trabajo y Economía Social.

d) Informar las estrategias y los programas de desarrollo y fomento de la economía social.

e) Realizar estudios e informes sobre cuestiones y problemas que afecten a la economía social y en especial sobre el refuerzo del conocimiento, presencia institucional y proyección internacional de la economía social.

f) Velar por la promoción y el respeto a los principios orientadores contemplados en el artículo 4 de la Ley 5/2011, de 29 de marzo, de Economía Social.

g) Emitir informe previo en la adopción de las medidas de información estadística de las entidades de economía social. 
h) Cuantas otras funciones y competencias se le atribuyan por disposiciones legales y reglamentarias.»

Por su parte, el apartado 3 queda redactado de la siguiente forma:

«3. Se entiende por economía social el conjunto de las actividades económicas y empresariales que, en el ámbito privado, llevan a cabo aquellas entidades que, de conformidad con los principios orientadores contemplados en el artículo 4 de la Ley 5/2011, de 29 de marzo, persiguen bien el interés colectivo de sus integrantes, bien el interés general económico o social, o ambos.»

El artículo 3 dedicado a su "Composición" es redactado de nuevo completamente, actualizando la misma. Por su parte, el nuevo Artículo 4 ("Funcionamiento") dotado de nueva redacción, no difiere sin embargo en lo esencial de su predecesor.

Se modifica la redacción del artículo 8 ("Comisión Permanente") y del articulo 12 ("Adopción de acuerdos. Actas del Consejo"), y al artículo 13 ("Grupos de trabajo.", se le añade un apartado 2:

«2. En los grupos de trabajo podrán participar personas expertas de reconocido prestigio designadas al efecto.»

Como adelantamos, también son modificadas diversas de sus disposiciones complementarias. No entramos en ello dada la naturaleza de la presente Crónica.

\section{VALORACIÓN}

Es difícil valorar la modificación de un órgano de esta naturaleza, máxime cuando la se trata de un órgano de carácter puramente técnico. Nos resta pues desearle suerte y eficacia en el cumplimiento de su misión, pues ahora más que nunca es preciso un verdadero enfoque social a la economía que sea real y efectivo. 